\title{
POÉTICAS DE LA IMPOSIBILIDAD: SAMUEL BECKETT Y BRAM VAN VELDE ${ }^{1}$
}

\author{
María Cecilia Salas Guerra
}

\begin{abstract}
RESUMEN
La experiencia de la melancolía ha sido largamente explorada por la literatura, el arte, la antropología, la iconología, gracias a lo cual es posible hablar de las imágenes de la melancolía en Occidente. Pero, por otras vías del pensamiento y de la creación, también es factible redescubrir las luminosas formas de lo que podemos denominar melancolía de la imagen, literaria y pictórica, la misma que anuncia la presencia de lo no discursivo y la inanidad del yo en la Modernidad. De ello dan cuenta las poéticas de la imposibilidad que se develan en el diálogo de Samuel Beckett con la pintura de Bram van Velde.

Palabras clave: Poéticas de la imposibilidad, silencio, deshabla, experiencia y pobreza.
\end{abstract}

\begin{abstract}
The experience of melancholy has been thoroughly explored in literature, art, anthropology, and iconology, thanks to which we can speak of images of melancholy in the West. But through other ways of thinking and creation, it is also possible to rediscover the brilliant forms of what we call the image of melancholy, literary and pictorial, which proclaims the presence of the the unspoken and the futility of self in Modernity. It brings to mind the poetics of the impossible that are revealed in Samuel Beckett's dialogue with the painting of Bram van Velde.

Keywords: Poetics of impossibility, silence, the unspoken, experience and poverty.
\end{abstract}

La escritura me ha llevado al silencio. [...] Sin embargo, tengo que continuar... Estoy frente a un acantilado y tengo que seguir adelante. Es imposible, verdad. Sin embargo se puede avanzar. Ganar unos cuantos miserables milímetros...

Beckett (2006)

A menudo uno alcanza el fracaso más que el éxito. En la pintura como en la vida. Hay que dejarse dominar.

Algo intenta nacer. Pero no sé lo que es. Nunca parto de un saber. No hay saber posible. Lo verdadero no es un saber. [...] La vida no está en lo visible. El cuadro me permite volver visible lo invisible.

Bram van Velde (2008)

\footnotetext{
María Cecilia Salas Guerra. Docente. Departamento de Estudios Filosóficos y Culturales. Universidad Nacional de Colombia, Sede Medellín.

Correo electrónico: mcsalasg@unal.edu.co
}

Recepción: 14- 04- 2012

Aceptación: 02- 05- 2012 


\section{Introducción}

En 1937 Samuel Beckett (1906-1989) traba amistad con el pintor holandés Geer van Velde (1898-1977), pero será la obra de su hermano mayor, Abraham van Velde (1895-1981) la que captará la mayor atención del escritor. Bram y Beckett vivirán una larga amistad -bastante fecunda para la obra de cada uno- marcada por el silencio la mayor parte del tiempo, de ello dan cuenta dos bellísimos textos de Charles Juliet, amigo de ambos artistas: Encuentros con Samuel Beckett (2006) y Una vida secreta, Encuentros con Bram van Velde (2008).

En "El mundo y el pantalón”, Beckett aclara que el taciturno Bram nació en octubre de 1895, "era el instante de las brumas"; mientras que Geer, nació en abril de 1898, "era el instante de los tulipanes" (2009). Bram es el pintor de la "duración", cercano al existencialismo, claramente antisurrealista - "lejos de las fantochadas de lo surreal"- y de camino hacia la más silenciosa abstracción, en suma, Bram trabaja donde "todo se adormece"; mientras Geer es el pintor de la "sucesión", más interesado por el poscubismo: en su pintura todo se mueve, nada, fluye, se deshace y se rehace. Interesa mostrar en este recorrido la gran relevancia que tuvo para Beckett el descubrimiento de la pintura de Bram, es decir, veremos cómo en los textos que el escritor le dedica al pintor no solo habla de éste y de su obra, no se ejercita como crítico, especialista o historiador del arte, sino que ante todo procede como aficionado, como espectador balbuciente, afectado por un acontecer visual frente al cual redescubre la impotencia de las palabras: una vez más, constata que la pintura es de lo que no se habla.

\section{La conciencia de lo no discursivo}

Yo comprendí que mi camino, al contrario (que el de Joyce), era el empobrecimiento, la renuncia y la emancipación del conocimiento; era restar más que sumar. Beckett (1996) $)^{2}$

Desde la década de 1930 el escritor irlandés enfrenta el mundo del lenguaje, de la palabra, en su alta soledad, allí permanece y su obra será el devenir de ese encuentro. De ahí que los humanos que transitan por sus libros, seres que apenas nombra, y que más bien se esfuerza en presentarlos en su condición de meros cuerpos: anónimos, condenados a la repetición, al absurdo, a la crispación sin sentido y a la espera; condenados, tal como se lee en "Sin", a un mundo de ruinas, gris ceniza, a un mundo de "Luz refugio / blancura rasa / rostros sin rastro / ningún recuerdo / lejanía sin /un cielo tierra confundidos / ni un ruido /nada / móvil" (Beckett 1997: 186). Mundo que en efecto bien puede persistir, incluso después de que en el mundo que creemos nuestro los cuerpos sucumban en la oscuridad y en el grado cero de la carne. Aquellos cuerpos de los que habla Beckett son ajenos a la historia, a los combates por un mundo mejor, a los proyectos y los procesos, a las iniciativas... Rumiando superfluidades o terribles contrariedades, o en silencio, y casi siempre inmóviles o desplazándose en círculos - para no dar la impresión de ir hacia alguien o hacia una meta determinada-, así, estos humanos parecen tocados - como los de Robert Walser- por los reinos de la muerte o de la locura; más aún, muchos de ellos parecen no haber nacido nunca: no saben si mueren o viven, no sabemos si antes enloquecieron y luego devinieron entes literarios o viceversa. Constituyen un puro existir, sin remisión en existencias particulares.

Es en 1937 cuando Beckett conoce a Bram van Velde, ese pintor silencioso y solitario incurable, padeciente como nadie del arte de pintar, busca eliminar lo accesorio y encontrar lo 
esencial, para quien la pintura es salvavidas pero también desprendimiento del mundo. En la pintura de Bram van Velde, el escritor descubre un espíritu afín, tanto por su modo de habitar el mundo como por la relación que sostiene con el arte, con los lenguajes de éste. Diremos que un punto de encuentro entre los dos artistas tiene que ver con la conciencia radical de lo no discursivo, la conciencia de imposibilidad de representar el objeto, pues ambos asumen la quiebra de la relación sujeto-objeto, pero no solo lo constatan sino que lo encarnan, habitan el extrarradio de la prolongada ilusión de un sujeto que cree representar e incluso conocer el objeto. Ambos enfrentan, cada uno a su manera, la pregunta "¿Qué queda de representable si la esencia del objeto es sustraerse a la representación?" (Beckett 2009: 149). Ante esta imposibilidad, Beckett emprende el arte de la despalabra (des-habla) y van Velde se refugia en la desconfianza hacia la palabra, pero sobre todo interesa aquí la manera como cada uno asume el reto de seguir: no tenemos más que palabras, dice Beckett, pero hay que seguir, y van Velde no puede pintar, pero pinta. Artistas que no son artistas entonces y que nos conducen por los abismales senderos del vacío, de la nada, en torno a lo cual edificamos variaciones del sentido. Artistas que muestran que la imagen (pictórica, literaria), está nimbada de melancolía, es decir, que arraiga en lo neutro del puro existir más allá de todo existente, en lo neutro del uno se aburre ${ }^{3}$.

Desde muy temprano en su obra, Beckett es un declarado escéptico frente a todo espíritu de sistema, y en lugar de éste o de algo que se le parezca, encarna más bien la alternativa del silencio, de la desidia, de la inacción, de la grisura del interminable hablar y de la espera por la espera, del no hacer o de la radical negación del obrar, evadiéndose así del mundo hacia el no lugar, del día hacia la noche, del discurso sistemático y del gran relato hacia la palabra escarpada. Pero esta grisura y esta pasividad -en cuyo seno se agita sin embargo la necesidad de seguir- tiene consecuencias, a saber, el exilio irremediable de sus personajes y de él mismo, pero también la incomodidad y extrañeza ante todo éxito posible. No es raro, por ello, que después de recibir el premio nobel en 1969 sienta que su casa se ha convertido en un burdel -como le confiesa a Charles Juliet-. Por esto mismo, Beckett es ajeno a las ideologías y a todo tipo de esperanza o ilusión mesiánica según la cual el mundo podría ser distinto de lo que es. En su temprano ensayo Proust, de 1930, asume que solo el arte puede dar refugio al hombre y salvaguardarlo de modo que no devenga un canaille.

En su célebre "Carta alemana" -escrita el 9 de julio de 1937 y dirigida a su amigo Axel Kaun- Beckett nombra, quizá sin proponérselo, los que serán principios fundamentales de su estética, más contundente aún que lo ya planteado en su ensayo Proust. Aquí se trata del paso decisivo hacia otro tipo de literatura, pues si la pintura se libera mediante la abstracción de la obligación de representar, y si la música no se ajusta ya al sistema tonal, entonces es necesario asumir decididamente que la literatura misma no puede más que abandonar sus lastres realistas, a esta búsqueda Beckett la denomina justamente "literatura de la despalabra, de la deshabla". Dicha carta es entonces una especie de manifiesto literario, es la génesis de la manera beckettiana. El escritor manifiesta su malestar con el inglés, su no hallarse en la lengua materna, confiesa a su amigo que padece una creciente dificultad de escribir en un "inglés formal. Mi propia lengua cada vez se asemeja más a un velo que he de hacer jirones para acceder a las cosas (o la nada) que hay detrás" (2009: 56).

De ahí que encuentre la gramática y el estilo tan caducos como un traje de baño Biedermeier ${ }^{4}$ (recatado, burgués, conservador) o como la impasibilidad de un caballero, como una máscara en todo caso. Ante este panorama, Beckett implora porque llegue el día en que la lengua se emplee con eficacia allí donde es maltratada eficazmente. En vista de que 
no podemos suprimir la lengua de una vez por todas, al menos no queremos dejar de hacer nada para favorecer su desprestigio. "Horadar en ella un agujero tras otro hasta que lo que se esconde detrás, ya sea algo o nada, comience a verterse poco a poco. No puedo imaginar un propósito más excelso para el escritor de hoy en día” (57). Y es que la terrible y arbitraria materialidad del habla le resulta a Beckett insoportable a estas alturas, tiene que existir un modo de disolverla y a tal propósito se apresta decididamente el escritor a partir de ese momento. ¿Cómo devorar el habla y lograr algo al modo de la séptima sinfonía de Beethoven, en la cual la superficie del sonido es devorada por enormes pausas negras, permitiendo así que en las pausas se escuchen, se perciban, insondables abismos de silencio? ¿Cómo no habría de disolverse también aquella "escalofriante y arbitraria materialidad de la superficie del habla"? "Se ruega respuesta" (57).

Es pues, hacia la necesidad del silencio hacia donde se orienta Beckett, y es así como reconoce que existen personas singulares, a quienes en absoluto les falta el silencio; las mismas que considera duras de oído, puesto que "en el bosque de los símbolos, que no son tales, los pajaritos de la interpretación, que no es tal, no callan nunca” (57). Así las cosas, y atrapados en semejante bosque, ya es mucho darse por satisfecho con poco. Por ejemplo, en principio puede tratarse de hallar de alguna manera, un sistema para representar por medio de palabras esa actitud sarcástica ante el habla. En esa disonancia entre el medio y su fin quizá ya sea posible percibir un susurro de esa música postrera o de ese silencio sobre el cual se agita Todo.

Aprovecha Beckett esta claridad meridiana acerca de lo que pretende, para señalar que esta búsqueda nada tiene que ver Joyce, quien ronda más bien la "apoteosis de la palabra. A menos que la Ascensión al cielo y el Descenso a los infiernos sean lo mismo" (57). Le resulta más probable que a su planteamiento se aproxime en algún punto Gertrude Stein ${ }^{5}$ con sus logografías, por lo menos allí se nota que el "tejido del lenguaje se ha vuelto poroso, aunque por desgracia de una forma accidental", "la desafortunada dama (¿vive aún?) sin duda sigue enamorada de su medio" (57-58), como lo está el matemático de sus números. En todo caso, nada tiene que ver el método de Stein con el de Joyce, eso sería tanto como comparar el nominalismo con el realismo.

Sin embargo, "Puede que alguna forma de ironía nominalista constituya en efecto una fase necesaria en el camino hacia esta literatura de la deshabla para mí tan tentadora. Pero no basta con que el juego pierda parte de su sagrada solemnidad. Tiene que acabar. [...] Un ataque (iconoclastia) a las palabras en nombre de la belleza. / Entretanto, no estoy haciendo nada" (58). Apenas, de tanto en tanto, dice tener el consuelo de maltratar involuntariamente una lengua, así sea extranjera, como en el caso de esta carta a su amigo Axel Kaun. Pero ya quisiera maltratar la propia lengua de forma consciente e intencionadamente, maltratarla "tal como, Deo juvante, lo haré" (58).

Estamos, pues, en 1937 ante un Beckett que se anuncia como despoblador del habla. En 1966, esta imagen cobrará la dimensión de la inquietante extrañeza, cuando escriba justamente el plomizo relato "El despoblador", donde se figura un pueblo enclaustrado en un cilindro (impregnado de la armonía entre el orden y el descuido), donde cada cuerpo va buscando cada uno su despoblador y donde "sólo el cilindro ofrece certezas, y en el exterior no hay sino misterio" (Beckett 1997: 193-213) ${ }^{6}$.

Búnker, zona extraña, ratonera humana, delirante campo de concentración de acechantes, trepadores y vencidos, refugio nuclear, exitoso panóptico, concentración de humanos arrasados en su singularidad y afectividad, desierto de cuerpos despoblados-desotrados-desterrados de la 
intimidad y de la alteridad más básica: impotentes por el clima; metáfora de variadas formas del totalitarismo. ¿Qué o quién es el despoblador o sin-patriador? ¿Cuál es el factor que despalabra estos cuerpos hacinados?

Estancia dantesca, ambiente próximo al mundo de los ciegos de Ernesto Sábato y José Saramago, al país de las últimas cosas de Paul Auster, al país de los trogloditas de Borges. Y también a Stalker (1979) y Solaris (1972), del director ruso Andrei Tarkovski. Estancia atópica donde tiene lugar el no lugar; escenario del absurdo donde tiene lugar una nada. Lugar aporético, sin poros, ni salidas, ambiente clausurado bajo un cénit que se niega a toda apertura o salida. Espacio recintado, foso circular, zona hermética y anárquica donde nadie manda ni parece mandar, solo el cilindro ordena, da certezas y garantiza la armonía. Espacio de igualación despersonalizada, fuera de discurso, ausencia de voces, imperio de las basculaciones de luz-clima, inercia de la más brutal actividad tantálica: expuestos a la desecación continua, privados u olvidados del lenguaje. Pueblo condenado a la clausura, condenados al desierto de la languidez. Pequeño pueblo de buscadores donde el primer hombre bajó la cabeza y cerró los ojos: vencido, ciego, ¿muerto en vida? El relato despuebla pues de todas las categorías que permitan la motilidad y el fluir de las palabras. Parábola de un infierno imaginario condenado a la repetición, en el cual la literatura de la deshabla ha llegado demasiado lejos con el Beckett de posguerra.

De regreso a la "Carta alemana" tenemos, pues, en 1937, a un escritor consciente de lo no discursivo y de cómo la literatura ha de habérselas con ello y atacar de frente lo que quiera que exista detrás del habla y de Todo, ya sea algo o nada, ya sea una cosa o silencio. La misión urge, pues la pintura y la música ya se han abismado por entonces en ciertas variaciones de la quiebra de la representación y del realismo.

Es justamente la variación que en este sentido adopta Bram van Velde, lo que al parecer atrae tanto a Beckett desde el primer momento, quizá porque en el pintor se trata de una experiencia radical con la imposibilidad y el fracaso: Bram es el silencio encarnado y hecho pintura luego, y ese modo de ser consecuente le interesa muchísimo a Samuel Beckett, quien, dicho sea de paso, durante la Guerra cuida de su amigo Bram, que ha dejado incluso de pintar, pero en 1942, Beckett -enrolado en la resistencia en París- huye de la Gestapo y será en 1945 cuando se reencuentren ${ }^{7}$.

Jordi Ibáñez Fanés muestra cómo en 1945 ambos artistas

reinventan una especie de primitivismo que no buscaría en lo exótico su fondo primordial sino más bien
en un individualismo exhausto, melancólico y al mismo tiempo enfrentado a una idea radical de verdad
o de autenticidad. Este primitivismo se articula como una forma de acabamiento, y por tanto no es un
primitivismo del origen sino del final de partida. (Ibáñez 2006)

Un primitivismo más cercano, en todo caso, a Walter Benjamin que a Gauguin; próximo más bien a Benjamin cuando, en "Experiencia y pobreza" (1933), aclara que ante la dificultad creciente en la modernidad por hacer traducible la experiencia en el lenguaje (y está hablando del efecto de la primera guerra, del auge urbano, del funcionalismo, de la estetización de la política, etc), es preciso al menos proceder como nuevos bárbaros (en sentido positivo): arrasar y empezar de cero, hacer con demasiado poco, poetizar la pobreza misma, sacar algo en limpio y algo decoroso de ella.

En este sentido, y dado que todo primitivismo es también un retorno de algo propio, demasiado incorporado, el del acabamiento preconizado por Beckett y van Velde permite 
igualmente, en palabras de Ibáñez "conjurar el mismo acabamiento para seguir haciendo algo, aunque sea algo sin importancia o con poco valor" (2006). En la Europa devastada de 1945 escribir o pintar o emprender cualquier forma de creación posible era sobre todo una decisión vital, por lo cual no es difícil imaginar en qué condiciones y bajo qué estado de ánimo se llevaba a cabo toda búsqueda creativa.

En 1937 Bram van Velde conoce también a Marthe Arnaud, una exmonja, misionera en Zambia, África, que había dejado su alma allí, horrorizada por las "maneras de los blancos". Desde que conoce a Bram -quien está apenas saliendo del duelo por la muerte de su esposaqueda extasiada con su obra y luego se convertirá en su pareja. Pero lo más importante aquí es que Marthe Arnaud le enseña las máscaras africanas, aunque ya en 1933 Bram había realizado -en Mallorca- una obra titulada Máscaras. O sea, que no es estrictamente una novedad para el artista, pero sí la ocasión para acercarse o configurar un primitivismo que, a juicio de Ibánez, no es ni formal ni conceptual, sino en cierto modo existencial, vital, e incluso moral.

En la misma época, 1936-1937, en medio de una prolongada crisis vital, Beckett viaja a Alemania, ante todo con el propósito de tener contacto directo con el arte, con la pintura. Recorre las ciudades de Hamburgo, Berlín y Dresde, pero, lamentablemente, su periplo alemán coincide con los cierres masivos -ordenados por Goebbels- de museos y galerías de arte contemporáneo donde se podían apreciar muestras del surrealismo, la abstracción, y en general, de lo que para el régimen no era más que "arte degenerado". Asiste pues como testigo del final de un mundo, constatando así la barbarie creciente de la civilización burguesa: testigo en todo caso de un proceso histórico que incide en el desnudamiento y la objetivación de la verdad interior: "Apatía y melancolía, nada ahora, nada después, solo envejecimiento y fealdad, nada en el pasado, excepto dolor y remordimiento", así se expresa Beckett en una carta escrita desde Munich, el 13 de marzo de 1937. Y en otra carta, del 26 de marzo del mismo año, dice: “¡nunca me he sentido más aletargado, estupidizado y con menos esperanzas en el futuro" (citado en Ibáñez 2006).

O sea que el encuentro Beckett-van Velde se produce en un momento de cristalización de la experiencia de la pobreza y de la devastación en distintos sentidos: el primero viene de ver la creciente barbarie en Alemania, tras lo cual ha escrito la mencionada carta o proyecto literario a Axel, y el segundo viene recién estrenado en una suerte de "primitivismo militante como experiencia de la visión interior" (2006). Beckett, por su parte, declara luego que su "escritura se desatascó cuando comprendió su propia locura y estupidez" (2006).

\section{Poéticas de la imposibilidad}

Rostros sin rastro blancura rasa mirada serena por fin ningún recuerdo. Beckett (1997)

Cuando ambos amigos se reencuentren en París en 1945 vendrán ya con una carga de melancolía, de escepticismo y de silencio exacerbado que marcará definitivamente la obra de cada uno. En 1946 Beckett empieza a escribir sus grandes obras, firmando así el pacto indeclinable de al menos manchar con palabras el silencio y la nada; escribe pues: Mercier y Camier (1946), Moloy (1951) Malone muere (1951), Esperando a Godot (1952) y El innombrable (1953). Es el mismo año de 1946 cuando se realiza una exposición -en el Salón de Mai de París- de los hermanos van Velde, para Bram será su primera vez, ya tiene cincuenta 
años y se siente fracasado, y aporta a la exposición veinticinco obras. Este será el pretexto para que Beckett escriba "El mundo y el pantalón”, que comienza con un chiste acerca de un cliente que reclama a su sastre que tarda mucho en confeccionarle un pantalón: "Dios hizo el mundo en seis días ¿y usted no es capaz de hacerme un pantalón en seis meses?... ipero mire usted el mundo y mire usted su pantalón!" (2009: 130). El chiste ampliado lo veremos luego en Final de partida. Al desastrado mundo se contrapone, como preferible, un pantalón pobre y miserable (¿Evocación de "El capote”, de Nicolái Gogol?).

En "El mundo y el pantalón" Beckett procede como aficionado que se distancia con profunda desconfianza del modo de hacer historia y crítica de arte -ámbitos donde no se deja nada al azar y donde no se ven obras sino estilos, periodos, pautas técnicas, es decir, que en lugar de acompañar la contemplación y abrir el discurso, se obturan posibilidades para la experiencia artística. Beckett se sitúa pues más allá del criticismo, dado que éste no vive la vida sino que se aísla de ella, de modo que la práctica convencional de la crítica la encuentra tan burda como querer hacer "histerectomías con palustre": "a mi qué me importa", de la crítica suelen salir cosas como: estética general, anécdota, catálogos razonados, o en último caso "parloteo agradable y confuso" (tal como denomina justamente lo que él mismo está haciendo) (2009: 131). Es imposible para Beckett, esa es su tesis, "decir nada sobre pintura", de modo que -más que hablar de los hermanos van Velde- habla de sí y de su ya comenzada para entonces andadura literaria y vital hacia el silencio interior, en lo cual coincide plenamente con Bram van Velde, encuentra en éste un camino ya recorrido en el silencio, en el fracaso y en la imposibilidad.

Se trata pues de dos artistas tocados por el cansancio y el desencanto teórico y por el escepticismo -sarcástico en Beckett-, que sin embargo no les paraliza sino que les empuja a seguir... Pero en época de posguerra es imposible salir en defensa del gran formato (a la manera Rotko) o de la estética de lo sublime, ni mucho menos, más bien adscriben lo antisublime, lo minimalista, lo antimonumental y precario: humor negro de Beckett y primitivismo interiorizado de van Velde.

Beckett, que parece vivir paralelamente al tiempo cronológico, como prescindiendo de la historia y de la política, consigna sin embargo en "El mundo y el pantalón” quizá la única opinión política que haya dejado escuchar en su obra:

\footnotetext{
Para terminar, hablemos de otras cosas, hablemos de lo "humano". 8

Es un vocablo y sin duda también es un concepto, que se reserva para los tiempos de las grandes masacres. Hace falta la pestilencia, Lisboa y una carnicería religiosa mayor para que los seres sueñen con amarse, con jorobar al jardinero de al lado, con ser sencillísimos.

Es una palabra que nos devolvemos hoy día con un furor nunca igualado. Diríase un dumdum.

Eso llueve sobre los medios artísticos con una abundancia muy particular. Es una lástima. Porque el arte no parece que tenga que necesidad de cataclismos para poder ejercerse. (2009: 144-45)
}

A este ritmo, insiste el autor, el día de mañana se le pedirá a la charcutería que sea humana. ¡Lo espantoso es que el artista no lo admita! Pero,

\footnotetext{
¿Qué llegará a ser, en esta feria (de lo humano, del humanismo), esta pintura solitaria de Bram van Velde, solitaria con la soledad que se cubre la cabeza, con la soledad que tiende los brazos?

Esta pintura cuya parcela menor contiene más humanidad verdadera que todas sus procesiones hacia una felicidad de cordero sagrado.

Supongo que será lapidada.

Están las condiciones eternas de la vida. Y está su coste. Maldición a quienes los distingan.

Después de todo nos contentaremos con abuchear. (2009: 145)
} 
Tenemos aquí el escepticismo más activo de Samuel Beckett, en nada parecido al repliegue subjetivista de las almas nobles. Es la fatiga teórica, pero también la fatiga combativa, expresión de la impaciencia que anida en el corazón de la paciencia, expresión de un malestar que no pretende ser inédito sino que ante todo se muestra como un final o acabamiento. Así, ambos artistas arriban cada uno en su campo a una especie de nueva experiencia de la visión y del lenguaje. Así, el tedio o cansancio teórico en Beckett y van Velde -celebrado irónicamente por el surrealismo, a la expresa distancia en relación con dicho movimiento- no propone en efecto nada nuevo ni programa alguno de restauración o renovación, más bien se abren a la fuga en todas las direcciones: hacia lo primario, lo vacío, lo pobre, lo absurdo, lo destruído, el retorno de lo mismo, lo neutro, el vaciamiento del sentido de la subjetividad y de la objetividad: melancolía de la imagen, de la literatura... No se trata aquí de la pregunta por el sentido que anima a la política y a la acción e incluso a cierta forma de la crítica, más bien se trata -con Beckett- de recavar un agujero en el habla, y -con Bram van Velde- de ahondar la desconfianza hacia la palabra y orientarse hacia el silencio y hacia lo desconocido. De este modo, ambos artistas deshablan la búsqueda del sentido y anteponen lo inencontrable, la imposibilidad del sentido mismo, el mundo como cilindro: tan amplio como para que toda búsqueda sea en vano y como para que toda tentativa de escapar sea igualmente vana.

En el tercero de los "Diálogos con Georges Duthuit", dedicado a Bram van Velde, Beckett insiste en esta disposición a la deshabla al referirse a la situación del pintor como "la de quien se siente impotente, no puede actuar, y llegado el caso no puede pintar, puesto que está obligado a hacerlo. Y el acto (de llegada) es el de quien, impotente, incapaz de actuar, actúa, y llegado el caso pinta, puesto que está obligado a hacerlo" (2009: 155). Por tanto, ¿diremos que van Velde es un artista que no es un artista? Tamañas son las afirmaciones de Beckett sobre el pintor. De ahí que se sienta hermano suyo, al declarar que su "pintura es inexpresiva" y que por tanto se halla en las antípodas de los grandes de la historia de la pintura, grandes que por definición han procurado escapar del fracaso mediante "relaciones más auténticas, más amplias, menos excluyentes, entre el que representa y lo representado, en una especie de tropismo hacia una luz respecto a cuya naturaleza las mejores opiniones no dejan de variar" (158). Lejos está van Velde de ese "automatismo idealizado", pues es "el primero en admitir que ser un artista significa fracasar, que el fracaso es su universo y rehuirlo es desertar, arte y oficio, buen cuidado del hogar, subsistencia" (158). Fidelidad al fracaso, o fracasar cada vez mejor, como nuevo término de relación en el arte, y disposición en procura de hacer de la imposibilidad de expresión, de la impotencia para actuar y luego actuar, hacer de ello una expresión: el arte como la expresión de que no hay nada qué expresar. Poetizar entonces la experiencia de la pobreza de experiencia, tal como diría Benjamin.

¿Pintar la nada del pintar, pintar el silencio que hay en el Todo? Samuel Beckett y van Velde parecen descubrir que no hay pintura ni escritura sin neutralizar el sí mismo, la individualidad, sin superarla en el sentido productivo, deviniendo en su lugar la voz, el él neutro del relato. Los hermanos van Velde, al igual que Beckett, son pues "artistas del impedimento", del fracaso y de la imposibilidad expresiva. De ello da cuenta Bram en el diálogo que durante varios años sostuvo con Juliet (2008):

Cuando uno llega hasta el fondo, descubre que no hay lugar fiable. Eso es lo que yo pinto. (59)

La pintura no vive más que por el deslizamiento hacia lo desconocido de sí misma. (86)

Las palabras no son nada. No son más que ruido. Hay que desconfiar de ellas. Cuando voy hacia el cuadro, encuentro el silencio. / Este mundo mecánico nos asfixia, la pintura es la vida. / La vida no está en lo visible. / El cuadro me permite volver visible lo invisible. (88) 
Fracaso e impedimento o la conciencia de disolución de la voluntad y de la yoidad, y del advenimiento de una segunda visión que no puede elegir o preferir lo luminoso en detrimento de lo oscuro e invisible, una segunda visión que no asume relación alguna del tipo sujeto-objeto. Beckett y van Velde coinciden en la poética del fracaso y el impedimento, del silencio y de lo desconocido, pero para ello es necesario saber de los propios límites, en el sentido de asumir que no se hace otra cosa que la se puede hacer.

Bram pinta la imposibilidad de pintar, Beckett literaturiza la imposibilidad de hacer literatura. De ahí que en "El mundo y el pantalón” Beckett en realidad está hablando de sus propias dificultades con la escritura, de modo que la declarada dificultad de hacer traducible la pintura en palabras es la misma intraducibilidad y el mismo sinsentido que ve perfilarse en la escritura y que, sin embargo, no le impide -más bien le obliga- escribir, pues hay que seguir... De la desconfianza de la escritura para con las imágenes, se avanza -en los diálogos con Duthuit- hacia la desconfianza frente a la pintura misma que fracasa en su cometido de plasmar algo verdadero y con sentido, más aún su sentido está en el fracaso y en el sinsentido, tal como el propio Beckett lo está viviendo ya con su escritura.

La pintura de la duración de Bram van Velde, es apertura al "tiempo que se adormece", a la oscuridad que ilumina el espíritu, al modo de la concepción blanchotiana de la literatura en cuanto luz que no viene tanto de arriba para hacer claro de bosque, sino que proviene de abajo, de la noche, para hacer presente lo desconocido en cuanto tal desconocido. Excepcional experiencia artística de la objetualidad, previa o contraria a todo, objetivismo razonado y pasado por el cálculo: a Beckett le interesa lo que hay en esa pintura de no razonado, de no combinado, de ingenuo y de mal tocado.

Ambos pintores, Geer y Bram, encarnan, a juicio de Beckett, dos obstáculos que siempre han estado en la pintura, sin ser representados; sin embargo, estos artistas procuran representarlos, a saber: el obstáculo cosa-objeto (Geer) y el obstáculo ojo-yo (Bram). Así, respectivamente, "no puedo pintar el objeto porque el objeto es el objeto", y "no puedo pintar el objeto porque soy lo que soy" (2009: 149). O sea que pintan lo que impide pintar. Estamos ante "una pintura de la aceptación, entreviendo en la ausencia de relación y en la ausencia de objeto la nueva relación (Bram) y el nuevo objeto (Geer)" (150).

Pero Beckett se detiene ante todo en el melancólico Bram, y en el "curioso efecto" que produce su obra hasta en el más avezado espectador: "le priva del uso de la palabra", no porque se trate de un "silencio del trastornado", sino de "un silencio casi se diría que de conveniencia, como el que se guarda, preguntándose por qué, delante de un mudo" (137-138).

\footnotetext{
La pintura de Bran van Velde sería pues en primer lugar una pintura de la cosa en suspenso, yo diría incluso de la cosa muerta, si este término no tuviera tan fastidiosas asociaciones. Es decir, que la cosa que se ve en ella ya no está solamente representada como cosa en suspenso, sino estrictamente tal como es, realmente coagulada, (cuajada, figée). Es la cosa a solas, aislada, por necesidad de verla, por la necesidad de ver. La cosa inmóvil en el vacío, he ahí, la cosa visible, el objeto puro. Yo no veo otro. (2009: 139)
}

¿Qué tanto suscribiría el propio van Velde esta comprensión de su pintura? En sus encuentros con Juliet insiste más bien en la pintura como experiencia de lo imposible, en pintar a tientas, a ciegas... Valga traer aquí la anécdota de las gafas que un día Bram encontró abandonadas, se las prueba, le gustan, le quedan bien, y las usa durante veinte años, hasta que en una visita al oculista éste le increpa con ironía: ¿cómo puede usted ver algo con esto? ¿A qué se dedica usted? A lo cual Bram responde apaciblemente: "Pinto mi vida interior" (Juliet 2008: 141). 
Ante su pintura interior, a punto de perder pie en la realidad, Beckett percibe que su teoría balbuciente sobre la pintura se hace tan apremiante y condicionante para Bram que opta por guardar silencio al respecto a partir de 1951, no sin antes esclarecer algo más sus consideraciones sobre Bram y su objetualidad. ¿A qué cosa se refiere Beckett cuando habla de la cosa? En "Pintores del impedimento", escrito por Beckett en 1948 para la exposición de Bram van Velde en Nueva York (que al parecer fue un fracaso, pero que al menos impresionó hondamente a De Kooning), señala con ironía para los norteamericanos que la Escuela de París no está en crisis, ni más faltaba, por el contrario, está en su florida juventud, pues tenemos a los hermanos van Velde, ellos son la garantía: "Ambos de luto por el objeto", "donde no llega el uno llega el otro", así que cuídense en Nueva York. La pintura del "impedimento para representar el objeto", y la novedad de esta conciencia. Tal impedimento da lugar a una realidad visual, pictórica, mental, y esa realidad es la ausencia del objeto. Es el Beckett jocosamente escéptico, irónico frente a los esencialismos de la filosofía moderna:

\footnotetext{
La historia de la pintura es la historia de sus relaciones con el objeto [...] Lo que renueva la pintura es en primer lugar que hay cada vez más cosas que pintar, y a continuación una forma de pintarlas cada vez más posesiva. [...] El primitivo escalofrío de la pintura al tomar conciencia de sus límites lleva hacia los confines de esos límites, lo secundario en el sentido de la profundidad, hacia la cosa que oculta la cosa. El objeto de la representación se resise siempre a la representación, ya sea a causa de sus accidentes, ya sea a causa de su sustancia, y en primer lugar a causa de sus accidentes, porque el conocimiento del accidente precede al de la sustancia.

El primer asalto contra el objeto captado, independientemente de sus cualidades, en su indiferencia, su inercia, su latencia, he ahí una definición de la pintura moderna, que no es seguramente más ridícula que otras. Tiene la ventaja, sin ser de ningún modo un juicio de valor, de excluir a los surrealistas [...]. (2009: 148)
}

Ibáñez considera que, en pasajes como este, Beckett da lugar a que pensemos que "la pintura es el resultado de la resistencia del objeto a la representación", el producto de un "fracaso visual", y por tanto, la imagen sería "la imagen de una ausencia, de un impedimento para captar el objeto tal como es" (2006). Por tanto, lo que vemos serían rasguños de un topo acostumbrado a la oscuridad. O, como dice Duthuit respecto de Bram: "una geometría abortada, unas coordenadas que se vienen abajo, un universo ciego, sordo", a primera vista impenetrable pero luego acaba entreabriéndose, "se huye de la asfixia en la asfixia" (2006). Bram avanza guiado por su instinto ultramiope. Ahora, ¿cómo podía ser visible esta pintura del hundimiento, que quiere hacer visible lo no visible, que escapa de las escuelas, que se anuda a lo conceptual? ¿De qué modo las melancolías de la imagen en Beckett y en van Velde -que en sí mismas son un desgarramiento del lenguaje metafísico conceptual y de la imagen moderna de hombreconstituyen ante todo modos radicales de poetizar la experiencia del vacío y del silencio?

\section{Notas}

1. Este texto es un avance del proyecto de investigación Arte y destrucción de la experiencia, adscrito al macroproyecto: Travesías estéticas y modernidades en las urbes contemporáneas. Imágenes, narraciones, espacios y subjetividadades, del Grupo de Estudios Estéticos. Universidad Nacional de Colombia, Sede Medellín. El texto amplía y reelabora la versión preliminar presentada en el II Encuentro Nacional de Investigadores en Estética y Filosofía del Arte, realizado en la Universidad Tecnológica de Pereira en el 2011.

2. Así se confiesa Beckett con su biógrafo James Knowlson en 1945. Esta misma diferencia con respecto a la escritura de Joyce -esa "apoteosis de la palabra"- se encuentra ya en la "Carta de 1937 en alemán" (Beckett 2009: 57) Sobre el camino de restar y renunciar, Francis Bacon dice respecto a Beckett -de quien afirma además que le sorprende que le comparen con él-: "Me pregunto si las ideas de Beckett 
sobre su arte no terminaron por matar su creación. Hay a la vez en él algo demasiado sistemático y demasiado inteligente, tal vez sea esto lo que siempre me ha molestado". Y, más adelante: "En pintura, siempre dejamos demasiados hábitos, nunca los eliminamos lo suficiente, pero en la obra de Beckett tengo con frecuencia la impresión de que, a fuerza de querer eliminar, ya no ha quedado nada y que esa nada acaba sonando a hueco...” (citado en Kundera 2009: 21. Entrevista con Michel Archimbaud). Respecto de lo cual replica el mismo Kundera: "Cuando un artista habla de otro, siempre habla (mediante carambolas y rodeos) de sí mismo, y en ello radica todo el interés de su opinión. ¿Qué nos dice Bacon sobre sí mismo al hablar de Beckett? Que no quiere ser clasificado. Que quiere proteger su obra de los tópicos".

3. De algún modo, en el diálogo cuasi silencioso de Beckett-van Velde, descubrimos variaciones tanto del pensamiento de lo neutro (según Levinas y Blanchot) y de las elaboraciones sobre el aburrimiento profundo (según Heidegger).

4. Biedermeier es el nombre de un gusto, de una literatura, de una corriente figurativa y de un estilo ornamental desarrollado en la época de la Restauración en el Imperio Austrohúngaro y en Europa Central.

5. En 1896 Stein publicó un texto sobre escritura automática, que se convirtió en una clave para las vanguardias. Digna de mencionar es la antipatía de la escritora por las comas, pues consideraba que dicho signo no sólo era un "puntapié al flujo verbal", sino un auténtico error existencial, dado que interrumpía el "presente prolongado" o el "presente continuo" en que Stein prefería escribir la realidad.

6. Dicho cilindro se describe como una vieja estancia de caucho, de muros muy gruesos, encerrada bajo un cénit que guarda su leyenda; estancia insonora de " $50 \mathrm{mt}$. de circunferencia por 16 de alto por armonía", tan amplia para permitir "buscar en vano", y tan limitada para que "toda escapatoria sea vana". Estancia habitada por una horda emocionalmente apática, indiferente, apacible, desatenta... pero sobre todo sin discurso, allí nadie habla, parecen expulsados de la lengua, y el omnisciente narrador es meticulosamente bizarro. Los cuerpos se hallan pues expulsados del cielo y de la tierra, en un limbo o purgatorio, ad portas del pandemónium. Peculiarísimo laboratorio humano, micromundo de numerosos trepadores y buscadores poseídos por la fiebre ocular, de un grupo menor de sedentarios que por un lapso no buscan, no miran; y de escasos cinco vencidos que ya abdicaron o se curaron de su fiebre ocular, cuyos ojos se apagaron definitivamente y sus cabezas se inclinaron para siempre: ciegos al fin por la fatiga de la búsqueda en vano y por la miseria moral. Los vencidos encarnan la carcoma o sanguijuela de la languidez o la melancolía: "sentados en su mayor parte contra el muro en la actitud que arrancó a Dante una de sus raras pálidas sonrisas” (1997: 195).

7. Para ver ejemplares de la obra pictórica de Bram van Velde consultar: http://www.mchampetier.com/ Bram-Van-Velde-83-es.html; o Bram van Velde (1990). Valencia: Instituto Valenciano de Arte Moderno y Centro de Arte Reina Sofía.

8. También en 1946 se escriben dos textos memorables: Jean Paul Sartre: El existencialismo es un humanismo, y Martin Heidegger: Carta sobre el humanismo.

\section{Bibliografía}

Beckett, Samuel. 1989. Proust. Barcelona: Península.

1990. Manchas en el silencio. Barcelona: Tusquets.

1997. Relatos. Barcelona: Tusquets.

2009. Disjecta. Madrid: Arena.

Benjamin, Walter. 1973. Discursos interrumpidos. Madrid: Taurus.

Cerrato, Laura. 1999. Génesis de la poética de Samuel Beckett. Buenos Aires: Fondo de Cultura Económica.

Ellman, Richard. 1990. Cuatro dublineses. Barcelona: Tusquets. 
Ibáñez, Jordi. 2004. La lupa de Beckett. Madrid: Visor.

Juliet, Charles. 2006. Encuentros con Samuel Beckett. Madrid: Siruela.

2008. Una vida secreta, Encuentros con Bram van Velde. Barcelona: Ediciones de la Rosa Cúbica.

Knowlson, James. 1996. Damned to Fame: The life of Samuel Beckett. London: Bloomsbury.

Kundera, Milan. 2009. Encuentros. Barcelona: Tusquets.

Martin, Jean-Hubert (Comisario) et al. 1990. Bram van Velde. Madrid: Centro de Arte Reina Sofía.

Villegas, Gerardo et al. 2006. "100 años de Beckett”. Casa del tiempo. 7 (87): 51-106. Ciudad de México: Universidad Autónoma Metropolitana.

VV.AA. 1990. Bram van Velde. Valencia: Instituto Valenciano de Arte Moderno y Centro de Arte Reina Sofía.

\section{Cibergrafía}

Ibáñez, Jordi. 2006. "Samuel Beckett y Bran van Velde o la reinvención del comienzo como final” [Archivo de audio]. En: Serge Guilbault (Dir.). Abstracción cálida y guerra fría. Curso de arte y cultura contemporánea. Barcelona: Museo de Arte Contemporáneo. http://www.macba.cat/controller.php?p_action=show_page\&pagina_id=33\&inst_ $\mathrm{id}=21664 \&$ lang=ESP. Consulta: 15 de mayo de 2011.

Van Velde, Bram. Estampas, litrografías, grabados, dibujos, libros ilustrados. http://www. mchampetier.com/Bram-Van-Velde-83-es.html. Consulta: 20 de mayo de 2011. 